\title{
Guillaume Heuguet
}

Electronic music history reloaded: Ishkur's online "Guide to Electronic Music 3.0".

Ishkur Guide to Electronic Music, by Kenneth John Taylor, https://music.ishkur.com/

In August 2019, the Ishkur Guide to Electronic Music had its last official update (3.0), a variety of media specializing in electronic music reported. ${ }^{1}$ The Guide is a hybrid between a chronological fresco and a diagram of the main musical genres, with which are associated files and musical extracts, in a dizzying parade, which runs from industrial / goth to UK Garage, passing by the more predictable Techno, House or Ambient.

The fact that this guide is in the news is welcome since the history of dance music culture has often focused on the importance of selected productions, parties, radio, and to some extent television, but web formats - from the first newgroups to the recent DJ livestream - are often bypassed. I myself encountered this guide when it was published at the very start of the 2000s, when I lived in a small town in the middle of France far from any club scene and where a search for "electronic music" on the main search engines and web directories yielded only a few pages of results. At a time when the simple fact of hearing the touchstones of music electronic could be a challenge, Ishkur's was providing a much needed catalog of around 100 references, all streamable from the site, both in mono or stereo - this last format being due to the fact that, as the author was putting it then, "a lot of the hardcore genres demand it". The access to musical sounds, in any case, was still a special event. Contrasting with the simple jingles and melodies in MIDI format accompanying the launch of a lot of

\footnotetext{
1 "Ishkur Quietly Releases His Fully Updated Guide To Electronic Music, 3.0", EDM.COM, accessed 20 August 2019 ; "La grande cartographie des musiques électroniques en ligne a enfin été mise à jour", Traxmag.com, accessed 22 August 2019.
} 
personal homepages, Ishkur's records were also sounding through the activation of Flash plugins, which had a semiotic and technical "thickness" to it contrasting with the text-image based HMTL pages, and thus enshrouded the sounds with a special audiovisual aura. These sounds were not only new and kind of mysterious (because of the dominant use of esoteric pseudonyms), but also functioning as something not-fully present, as an evasive trace of "the real record". Due to the obvious compression and poor quality of most audio processing chains of personal computers and their speakers, they appeared semiotically thicker than most other online experiences.

A guide like Ishkur's could then serve as a rare global reference for an audience living far from the main creative hubs, raves and clubs, alongside a handful of magazines, record stores and books that were not always easy to get hold of.

In this context, the Ishkur guide had the aura of a kind of treasure map, placing users in the position of pioneers experimenting and playing with a new kind of gadget, and carriers of a kind of universalist curiosity — with the nuance that this affective structure, pervasive in the early days of the general public web, was here applied to a subject of emerging and niche interest: if in theory everybody could access the site, the original layout and the knowing tone were both part of its broader appeal and drawing a line with potential "web tourists".

Since the guide was first published in 2000, the Web has of course been transformed from a space for learning and knowledge into a media landscape dominated by advertising agencies and platforms where a good part of music that passes endlessly risks what some have called "the collapse of the context". Almost 20 years later, the Ishkur guide therefore functions as a sort of touchstone, which reflects a utopia that is both lost and more current than ever. It can 
be situated alongside resistance fighters such as Wikipedia, the Internet Archive, Ubu Web, or other pseudo-encyclopedia projects organized by a single author, such as the Art and Popular Culture Encyclopedia available at www.jahsonic.com. This is why it now offers an interesting resource for contemporary music and sound historians, not so much as an authoritative source for an academic history of electronic music, but more as an index to the building of an electronic music culture in relation to media and technologies, to the way audiences' relationships to electronic music have also been defined with regard to things like the mediality of compressed online sounds, DIY encyclopedic practices, and experiments with digital software standards and web formats.

The irony is that Ishkur's almost quixotic initiative to build a synthetic map of the contours of dance music culture is now competing with some of the world's biggest companies, such as Google's Music Timeline (https://music-timeline.appspot.com/) supposed to account for the popularity of different musical genres in history based on Google Play usage statistics and external information.

Of course, music genres (and their borders) as well as genericity (and its logics) have always been a great subject of discussions and controversies for both music lovers and scholars, as exemplified by a current of works on genre building published during the past decade (Wald 2009, 2012; Brackett 2016) and by recent conversations pointing to an "end of genres" (Harper 2012) and their relationship to formats in music streaming (Weisbard 2014; James 2017; Pelly 2018) The meaning of genres depends on what my French colleagues in media studies call "semiotic predilections", by which they mean the choice of a particular material anchor for interpretation: in this case, "speaking of genre" might be related to practices of production, stylistic (sounding) family likeness (in the Wittgensteinian sense), or communities 
of use (be it through specific ways of dancing, collecting, or writing about these sounds). They also rely on specific mediations in the institutionalization of meaning, from the record shop to the radio by way of the DJ and the (popular) historian of music. It is by situating "music genre building" as not so much a descriptive but a performative activity, which is always-already polyphonic, that we can compare Ishkur's Guide to Google's Timeline. Indeed, despite their different projects, they bring out two conceptions of knowledge about music that are currently competing in public space, even if they rarely confront each other head-on. One, contemporary and dominant, is based on the pretense to analyze the behavior of listeners and on a strictly quantitative criterion of popularity as an indicator of what matters. As such, it tends to turn musical genres into nominal realities and black boxes: genres succeed one another rather than superimpose or decompose. They seem frozen once and for all, and are not articulated with other things: cities of origin or mythologized as in the case of Detroit techno; production methods, as with the importance of Roland machines in House; sound parameters in reception, as in Funky House, critical speeches, media fashions, etc.

The other relationship, represented by Ishkur, is based on a definition of genres not as an ontology but as a practice and discourse in its own right, an effort to objectify rather than represent truth: a quarrel par excellence. As a counterpoint to the tendency of certain amateurs to denounce genres as a superfluous and imprecise reference, Iskhur both uses and discusses genres. He treats genres as essentially unstable categories, a fact that has also been revealed in the past decade by the multiplication of specific "style tags" instead of unique genres in a number of streaming services . By taking this instability into account rather than trying to deny it, Ishkur helps us understand how a sound and musical culture is built. 
The fact sheets offered by Iskhur are actually written in a way that is often less synthetic and didactic than critical. They are in fact often less presentations than meta-comments, reacting to canonical tales of the history of genres by problematizing for example the moment when the same musical genre (electro) is renamed (to become Techno), exaggeratedly extended, then reduced and canonized from a European point of view regarding the history of a city (Detroit Techno). On this subject in particular, Ishkur is careful to circumvent the fetishist and retrospective narratives, and to take into consideration the complexity in terms of class and identity.

Of course, the very choice of a timeline doesn't allow much for the non-linear takes on aesthetic history which are a strong part of electronic music culture. This non-linear approach has been built from the 1990's onwards, in the poetics of liquidity related to "ambient" listening (Toop 1995) or in the use of the metaphor of the rhizome in books like Reynolds' Energy Flash (Reynolds 1998). It is still present in the contemporary notion that electronic music might not be so much about a series of avant-gardist "shocks of the new" or any kind of teleological progress (Reynolds 2011), but more about the diasporic dissemination of tropes (Eshun 2018); a dialectical saving of lost futures (Fisher 2014); or a break from the process of music's rationalization (Harper 2017). This fact is most manifest in the current releases of reissues, explicitly unearthing potential and still-relevant futures in forgotten pasts in a way that echoes Benjaminian conceptions of history (Löwy 2005). ${ }^{2}$

On this point, the addition of a section on pioneers is of particular interest. The status of this keyword in the Guide (which works almost like a genre in the promotional-critical texts of major underground retailers like Boomkat (https://boomkat.com/)) is not clear, even if we can

\footnotetext{
${ }^{2}$ See for example the Music From Memory label's "Uneven paths: Deviant Pop From Europe 1980-1991" (2018).
} 
appreciate Ishkur's decision not to conflate it too much with more highbrow genres and scenes such as Musique Concrete, Experimental and Minimalism. Ishkur thus allows for an understanding of the importance of the gap between the avant-garde of the past focused on sound practices and techniques, and the set of genres and scenes which arose as "electronic dance music" - another interesting choice here being the incorporation of novelty records at the same level with other, more predictable and revered avant-garde figures.

On the other hand, Ishkur's definition of a heavily-loaded category like Experimental seems a bit faint: in contrast to more popular dance music genres, theoretical writing by composers on the category itself abounds, as well as works of scholars showing for example how the uses of the word does not always distinguish between the two opposed?? initial uses by Schaeffer and Cage for two very different projects - one focused on sonic experiments on the model of science, the other stressing the pragmatic aesthetics of at least partly open-ended practices (Saladin 2017). However, the musical examples chosen for this genre are pretty interesting, as they encompass lesser known projects such as Autistici, 2cb, or Mind over Midi, alongside better-known artists playing with the power of analog sources of noise, such as Einstürzende Neubauten, and the process of recording, like Oval. In fact, each genre's playlist, being unordered, non-hierarchical and bearing neither commentary nor justification, provides a site of departure for stimulating disputes over canon formation. The "Krautrock" playlist, for example, includes contemporary artists as varied as Prins Thomas (more often indexed as nudisco since his rise in the middle of the 2000s, but incorporating longer chord progressions and flute textures inspired by Krautrock in his song title " $\mathrm{C}$ " directly referencing Can) or an early ambient-drone piece from Oneohtrix Point Never that uses open-ended vintage synth melodies. Another interesting debate arising from this kind of choices is the trend for "electronic music" maps and histories to grow toward positing the genre as an all- 
encompassing, cross-genre aesthetic, which allows for the incorporation of hip-hop and even "indie" (with songs toying with guitar-and-effects arrangements from Beck, Destroyer or The Notwist).

It is of course impossible to cover here in detail the sometimes very funny and accurate, sometimes disturbing and a bit too definitive takes Ishkur takes on each genre. Nonetheless, in order to address the ambivalence of the project, it is interesting to finish by returning to the general visual layout of the Guide. In its updated form of straight thin lines and dots, it connotes science - especially in comparison to the original, with its $3 \mathrm{D}$ typos paradoxically very current in the context of a revival of rave culture. But in the background of the diagram, we find faint pictures of circuitry, an interesting if classic metaphor of the functioning of musical culture, with feedbacks, thresholds and levels that inform some popular music studies works such as David Novak’s Japanoise (Novak 2013).

Ishkur's guide is all about this kind of tension, between an apparent pseudo-transparent logical frame and vernacular web imagery, between a bit too convenient shortcuts and clever references; oscillating between a graphic flattening of genre histories and a display of its dense stratification, even allowing a few subgenres to cross across umbrella categories, as they often do. In the end, by searching for immediate visual-sonic impact as well as textural nuance, by displaying qualities of novelty and fun, by playing with para-scientific and pseudo-objective rhetoric while provoking proper critical thought, Ishkur's guide mimics the dynamics of electronic dance culture itself.

Notes on contributor

Guillaume Heuguet holds a PhD in Sciences de l'information et de la communication / Media Studies from Sorbonne University, where he directs the Transnum research program. He is a 
member of the research labs GRIPIC (Sorbonne University) and IRMECCEN (Sorbonne Nouvelle) and the chief editor of the music critic journal Audimat. His work analyses the transformations of musical culture and digital media under capitalism and he is co-editing with Gérôme Guibert the forthcoming French reader Thinking popular music. An anthology of popular music studies (Philharmonie of Paris / La Rue Musicale).

\section{References}

Brackett, David. 2016. Categorizing sound: genre and twentieth-century popular music. Oakland: University of California Press.

Eshun, Kodwo. 2018. More brilliant than the sun: Adventures in sonic fiction. London: Verso.

Fisher, Mark. 2014. Ghosts of my life: Writings on depression, hauntology and lost futures. Winchester: John Hunt Publishing.

Harper, Adam. 2012. "What happened to genre?” Dummy, August 14. Accessed 3 July 2020. http://www.dummymag.com/features/adam-harper-whatever-happened-to-genre

Harper, Adam. 2017. "How Internet music is frying your brain.” Popular Music 36 (1): 8697. doi:10.1017/S0261143016000696

James, Robin. 2017. “Songs of Myself.” Real Life. May 31. Accessed 25 June 2018. http://reallifemag.com/songs-of-myself/

Lövy, Michael. 2005. Fire alarm: Reading Walter Benjamin's On the concept of history. London: Verso.

Novak, David. 2013. Japanoise: Music at the edge of circulation. Durham: Duke University Press.

Pelly, Liz. 2018. "Streambait pop.” The Baffler. December 11. Accessed 3 July 2020. https://thebaffler.com/downstream/streambait-pop-pelly

Reynolds, Simon. 1998. Energy flash: A journey through rave music and dance culture. London: Picador.

Reynolds, Simon. 2011. Retromania: Pop culture's addiction to its own past. London: Macmillan.

Saladin, Mathieu. 2017. "Les musiques "expérimentales", une polémique en devenir." Audimat 7: 186-207.

Toop, David. 1995. Ocean of Sound: Aether Talk, Ambient Sound and Imaginary Worlds London: Serpent's Tail.

Wald, Elijah. 2009. How the Beatles destroyed rock'n'roll: An alternative history of American popular music. Oxford: Oxford University Press. 
Wald, Elijah. 2012. Escaping the Delta: Robert Johnson and the invention of the blues. New York: Harper Collins.

Weisbard, Eric. 2014. Top 40 democracy: The rival mainstreams of American music. Chicago: University of Chicago Press. 